www.jmscr.igmpublication.org

Impact Factor (SJIF): 6.379

Index Copernicus Value: 71.58

ISSN (e)-2347-176x ISSN (p) 2455-0450

crossref DOI:_https://dx.doi.org/10.18535/jmscr/v6i3.107

Journal Of Medical Science And Clinical Research

IGM Publication

An Official Publication of IGM Publication

\title{
Gender independent Monitoring of Hepatotoxicity with the help of Hepatic Aminotransferase Level as a Prognostic \& Tolerance tool-DOTS Patients
}

\author{
Authors \\ Dr Karuna Thakur (Assit. Prof.), *Dr Ramu Thakur (Assit. Prof.) \\ MGM Medical College with M.Y. Hospital Indore M.P, India \\ Corresponding Author \\ *Dr Ramu Thakur( Assit. Prof.) \\ MGM Medical College with M.Y. Hospital Indore MP, India \\ Mob: +919977126168, Email: ramuthakur170@gmail.com
}

\begin{abstract}
Aims \& Objectives: To study the status of liver functions in patients of multidrug resistant tuberculosis. To asses the prevalence of hepatotoxicity in these patients. To compare and correlate this hepatotoxicity with possible culprit drug/combination and other associated factors. To study the hepatotoxicity of second line antitubercular drugs in patients receiving second line antitubercular drugs..

Material \& Methods: This will be a prospective, clinical and epidemiological study of hepatotoxicity in patients of MDR tuberculosis. Consenting individuals will be chosen, cases will be consecutive patients attending various indoor and outdoor facilities of J.A. Group of Hospitals of Gajra Raja Medical College, Gwalior. Those patients who are on treatment with second line antitubercular drugs will be selected for study. Cases will undergo (1) Complete history(2) Clinical evaluation (3) Investigation for the diagnosis of the hepatotoxicity. All the relevant information will be recorded in a pre-designed proforma for the analysis of the result.

Conclusion: It has been observed that the hepatotoxicity which is very common as well as fulminant in patients on treatment with first line antitubercular drugs has not been found even in a single patients second line antitubercular drug inspite of a very long duration of treatment compared to short term chemotherapy even though rifabutin, roxithromycin and azithromycin are known to have their toxic effects on liver.
\end{abstract}

Keyword: Rifabutin, hepatotoxicity, Antitubercular.

\section{Material \& Methods}

Study area and design- This will be a prospective, clinical and epidemiological study of hepatotoxicity in patients of MDR tuberculosis. Consenting individuals will be chosen, cases will be consecutive patients attending various indoor and outdoor facilities of J.A. Group of Hospitals of Gajra Raja Medical College, Gwalior.
Those patients who are on treatment with second line antitubercular drugs will be selected for study.

Cases will undergo (1) Complete history

(2) Clinical evaluation

(3) Investigation

for the diagnosis of the hepatotoxicity. 
All the relevant information will be recorded in a pre-designed proforma for the analysis of the result.

Ethical consideration-Take informed consent was obtained from all study participant. Start proper management as a guide line.

\section{Patient's selection criteria}

\section{Inclusion Criteria}

1. All consequetive patients of MDR tuberculosis newly started and already on treatment under various combinations of reserve drugs.

2. Consenting patients with all co ordinations.

3. Patients willing for necessary investigations.

\section{Exclusion Criteria}

1. Patient not suffering from tuberculosis.

2. Patient not on second line antitubercular therapy

3. Patients with preexisting hepatic derangements due to some other systemic illnesses

4. Non consenting individuals

\section{Observation \& Discussion}

Age Distribution of Cases

\begin{tabular}{|l|c|c|c|c|c|c|c|}
\hline S.NO. & \multirow{2}{*}{$\begin{array}{c}\text { AGE } \\
\text { (yrs) }\end{array}$} & \multicolumn{2}{|c|}{ Males } & \multicolumn{2}{c|}{ Females } & \multicolumn{2}{c|}{ TOTAL } \\
\cline { 3 - 8 } & NO. & \% & NO. & \% & NO. & \% \\
\hline 1. & $14-20$ & 04 & 08 & 01 & 02 & 05 & 10 \\
\hline 2. & $21-30$ & 10 & 20 & 07 & 14 & 17 & 34 \\
\hline 3. & $31-40$ & 08 & 16 & 04 & 08 & 12 & 24 \\
\hline 4. & $41-50$ & 07 & 14 & 00 & 00 & 07 & 14 \\
\hline 5. & $51-60$ & 07 & 14 & 00 & 00 & 07 & 14 \\
\hline 6. & $>60$ & 01 & 02 & 01 & 02 & 02 & 04 \\
\hline & TOTAL & 37 & 74 & 13 & 26 & 50 & \\
\hline
\end{tabular}

In the study group, patients of age between 18 years to 65 years were included. Majority of patients (34\%) fell in 21-30 years of age group.

Distribution of Cases According to Alanine Aminotransferase Level

\begin{tabular}{|l|c|c|c|c|c|c|c|}
\hline S.No. & SGPT & \multicolumn{2}{|c|}{ Males } & \multicolumn{2}{c|}{ Females } & \multicolumn{2}{c|}{ Total } \\
\cline { 3 - 8 } & (in U/L) & No. & \% & No. & \% & No. & \% \\
\hline 1. & $<41$ & 30 & 60 & 09 & 18 & 39 & 78 \\
\hline 2. & $41-400$ & 07 & 14 & 04 & 08 & 11 & 22 \\
\hline 3. & $>400$ & 00 & 00 & 00 & 00 & 00 & 00 \\
\hline
\end{tabular}

In the study group maximum number of patients (78\%) had SGPT less than $41 \mathrm{U} / \mathrm{L}$. None of the patients had SGPT value in the range of hepatotoxicity.

\section{Distribution of Cases According to Aspartateaminotransferase Level}

\begin{tabular}{|l|c|c|c|c|c|c|c|}
\hline S.No. & $\begin{array}{c}\text { SGOT } \\
\text { (in U/L) }\end{array}$ & \multicolumn{2}{|c|}{ Males } & \multicolumn{2}{c|}{ Females } & \multicolumn{2}{c|}{ Total } \\
\hline & & No. & \% & No. & \% & No. & \% \\
\hline 1. & $<38$ & 14 & 28 & 04 & 08 & 16 & 32 \\
\hline 2. & $38-190$ & 23 & 46 & 09 & 18 & 34 & 68 \\
\hline 3. & $190-380$ & 00 & 00 & 00 & 00 & 00 & 00 \\
\hline
\end{tabular}

In the study group, maximum number of patients $(68 \%)$ had SGOT values between $38 \mathrm{U} / \mathrm{L}$ to 190 U/L. none of the patients had increase in SGOT value up to hepatotoxicity level.
Data analysis in following hematological parameters with the difference under the Extended Mantel-Haenszel test for trend of chi -Squares test. Chi-sq. test X2 Value $=0.873[\mathrm{DF}=1] 2$ - 
sided $\mathrm{P}=0.350$ For trend in a given direction: $\mathrm{P}$ $=0.175$

\section{Conclusion}

Those cases who are on treatment with second line antitubercular drugs were selected for study. the cases were evaluated with complete history, clinically and were subjected for relevant investigations for the diagnosis of hepatotoxicity. All the relevant information was recorded in a pre-designed proforma for the analysis of the result. In present study, out of 50 cases, 37(74\%) were males and 13(26\%) were females. which quite correlates with a previous study conducted by SAARC ${ }^{137}$ namely "Gender Differences among Tuberculosis Cases in National TB Control Programmes within SAARC Countries"; it was found that gender difference between the cases in India undergoing sputum examination was quite evident with 4188 cases out of 6374 being male and 2186 being females, out of these cases $747(17.8 \%$ of males) males and 306 (14\% of females ) showing sputum positivity . the reason for the same can be multifactorial ; one of them being that in India females confront many genderbased inequalities. Such inequalities may impose an impact on female's health in terms of their poor health seeking behavior and obtaining health care services. This study results support the development of a number of hypotheses such as males are more susceptible to TB infection, females have poor health seeking behavior/access problem, females are differently treated at health care units, and quality of sputum produced by female TB suspects affects the diagnosis. Further studies are needed to find out definitive causes for gender differences in TB epidemiology.

Cases were of age group 18 years to 65 years, with majority of cases from age group 21 years to 30 years. Productive age group i.e. from 21 years to 40 years constituted $58 \%$ of the study sample. This study corresponds to a report published by $\mathrm{WHO}^{138}$ in 2002 in which $81.6 \%$ of 190149 of smear positive cases presented in year 2000 in India in range of 15-55 yrs of age group. But statistically no significant correlation was observed.

Tuberculosis is known as 'wasting disease'. This is well reflected in the present study as maximum $(40 \%)$ of the cases had BMI less than $18.5 \mathrm{~kg} / \mathrm{m}^{2}$. Among all these cases in a study conducted by Leung C.C. et $\mathrm{al}^{139}$ a study involving correlation of tuberculosis and BMI was done, revealing that obesity is related to decreased risk of pulmonary tuberculosis in elderly age group. Similarly a study conducted by Lettow M V et al in revealed that pulmonary tuberculosis was associated with low BMI, whether in HIV positive or negative individuals, with about $1 / 3^{\text {rd }}$ of all cases lying below $17 \mathrm{~kg} / \mathrm{m}^{2}$. Hence it can be safely assumed that BMI is inversely related to pulmonary tuberculosis and vice versa.

In this study, it was observed that maximum number of cases (32\%) who developed MDR TB were unemployed and about $62 \%$ cases fell in class I to III of socio economic status reflecting that the financial affordability plays an important role in compliance and adherence of the patient to the treatment of tuberculosis.

The study group contained cases of educational status from illiterate up to graduate, with majority of cases $(66 \%)$ educated to middle class reflecting the poor literacy being major contributor in the development of drug resistant cases as it determines that awareness of cases for antitubercular treatment which is reflected in patients' compliance and adherence to the treatment.

The treatment taken by the cases prior to the presentation was evaluated and it was found that there was no patient in dots category 1 and 3, the reason for this could be attributed to the fact that when cases fail on these drugs they are shifted to category 2 treatment for dots rather than considering them to be primary MDR cases. In this study, it was observed that majority of cases (84\%) who developed drug resistant tuberculosis had a history of receiving NON DOTS ATT. DOTS regimen should be strictly followed and patient should be advised to take treatment 
regularly so that the default rates among the patients of tuberculosis is reduced.

If no improvement or deterioration is observed during treatment with first line antitubercular drugs, patient should be screened for drug resistance.

Evaluation of drug resistance should be available at each tertiary care centres so that the treatment can be given properly as per the drug resistance.

The patient should be counseled before advising antitubercular treatment to the patient so that the compliance for the same can be assured and the patient should be encouraged to visit the doctor routinely for the check up so that his compliance for the drugs can be monitored and any complication which may lead to patient refraining from DOTS or other antitubercular treatment should be managed accordingly.

Duration of treatment was being taken into consideration including the beginning of treatment, default, symptom free period, and continuation of treatment. Majority having history of taking first line ATT for $>1$ years. This indicates that the irrational and inadequate use of ATT plays an important role in development of drug resistance.

It was also observed that only 3 out of 50 cases (6\%) had an associated co morbid illness i.e. DM which bears no statistical significance.

Out of 50 cases in the study group, $48 \%$ cases had history of tobacco smoking, indicating that smoking plays an important role in increases susceptibility to tuberculosis infection. Similarly in a study done by Chiang CY ${ }^{140}$ et al noted a strong correlation between smoking and pulmonary tuberculosis. According to them, smoking (both active and passive) is more likely to have active or relapse in pulmonary tuberculosis.

Similarly study of parameter of alcoholism showed a highly significant association between alcoholism and pulmonary tuberculosis with a correlation value of 0.599 and a $\mathrm{p}$ value of .001 . in a study conducted by Fleming $\mathrm{M} \mathrm{F}^{\mathbf{1}}$ et al (2006) it was found that alcohol abuse was related with 8 fold increase in resistance, and increased morbidity. In this study, 8 out of 50 i.e. $16 \%$ cases had history of alcohol addiction. Majority of cases $(86 \%)$ in the study group presented with complain of loss of appetite reflecting the ongoing tubercular disease activity. Significant number of cases $(80 \%)$ had complain of breathlessness which may be partly due to associated COPD due to chronic smoking.

Most common radiological involvement in cases of multidrug tuberculosis was upper ling field with infiltrative lesion indicating the active lesion in apical lobe. correlating with a study done by Gomes et al in 2001 it was found that Parenchymal-infiltrate lesions are the most frequent radiological manifestation of pulmonary tuberculosis. and they are generally associated with cavities.

In this study, maximum number of cases $(58 \%)$ of cases had sputum positivity of $3+$ indicating the high level of infectivity in these cases. This further stress the need of taking adequate measures to treat the MDR tuberculosis so as to prevent its further spread in the community and development of XDR TB.

The cases included in this study had history of treatment with various drug regimens of second line antitubercular drugs. From two drug to seven drug combinations. Out of 50 cases, 26(52\%) were receiving six drug regimen, with most common being combination of Kanamycin, Rifabutin, Prothionamide, Levofloxacin, Cycloserine and Clofazimine. Maximum number of cases $(62 \%)$ had history of taking second line antitubercular drugs for the period of 2 months to 6 months.

Out of 50 cases included in study, 7 (14\%) of cases were on Amikacin and 39(78\%) were taking Kanamycin. None of them showed hepatotoxicity which correlates with the study Prasad R et al. ${ }^{57}$ which concluded that in MDR-TB patients, regimen consisting of ethionamide, isoniazid, PAS and cycloserine and kanamycin appears to be effective and safe.

In present study group, 34(68\%) cases were taking Prothionamide and 13(26\%) were taking Ethionamide which correlates with the study done 
by Fajardo Tranquilino $\mathrm{T}$ et $\mathrm{al}^{58}$ which reported ethionamide and prothionamide to be safe. While Ian McNicholl et al. ${ }^{54}$ reported hepatotoxicity in $2 \%$ of cases receiving ethionamide and Pattyn SR et al. ${ }^{56}$ reported hepatotoxicity due to ethionamide and recommended for its dose reduction. TRANQUILINO T. FAJARDO et at. ${ }^{55}$ which reported hepatotoxicity due to prothionamide in 1 out of 50 patients.

Out of 50 cases, 49(98\%) of cases had history of taking Levofloxacin. none of them developed hepatotoxicity which is in correlation with the US Food and Drug Administration ${ }^{50}$. Though few cases of hepatocellular injury has been reported by Tina Papastavros et al. ${ }^{48}$, Anita Karim et al. ${ }^{49}$, Sahin Coban MD et $\mathrm{al}^{51}$ and Miguel F. Carrascosa MD et al. ${ }^{53}$.

$41(82 \%)$ cases in the study group had history of treatment with Cycloserine. None of the patients in Cycloserine group showed hepatotoxicity which is in accordance with Prasad R et al. ${ }^{57}$ which reported Cycloserine to be safe and effective in treatment of MDR TB. While Ian McNicholl et al. ${ }^{54}$ reported hepatotoxicity due to Cycloserine.

\section{References}

1. Palomino $\mathbf{J} \mathbf{C}$ et al. Tuberculosis 2007From basic science to patient care.

2. Flick LF. Development of knowledge of tuberculosis.

Philadelphia:

Wickersham;1925

3. Webb GB. Tuberculosis: Hoeber; 1936

4. Rosenblatt MB. Pulmonary tuberculosis: evolution of modern therapy. Bull NY Acad Med 1973;49:163-96

5. Rubin SA. Tuberculosis. The captain of all these men of death. Radiol Clin North Am 1995;33:619-39.

6. Mangett JJ. Sepulchretum sive natomica practice, vol 1. Observatio XLVII[3 vols]. London: Cramer and Perachon;1700.

7. Dubos R, Dubos J. The white plague. Tuberculosis, man and society. Boston: Little, Brown and Company; 1952
8. Keers RY. Pulmonary and osseus tuberculosis. A journey down the centuries. London: Bailliere-Tindall; 1978

9. World Health Organisation. WHO report 2008. Global tuberculosis control: surveillance, planning, financing. WHO/ HTM/TB/2008.393. Geneva: World Health Organisation;2008

10. World Health Organisation. Antituberculosis drug resistance in the world. Report No. 4.. WHO/IUATLD Global Projest on Anti-tuberculosis Drug Resistance Surveillance. WHO/HTM/TB/2008.394. Geneva: World Health Organisation;2008

11. Calmette A. Tubercle bacillus infection and tuberculosis in man and animals [ translated by Soper WB, Smith GB]. Baltimore: Williams and Wilkins; 1923.

12. Benichou C. Criteria for drug-induced liver disorder: report of an international consensus meeting. J Hepatol 1990;11:272-276.

13. Chitturi S, Farrell G. Drug-induced liver disease. In: Schiff ER, Sorrell MF, Maddrey WC, editors. Schiff's diseases of the liver, 9th ed. Philadelphia: Lippincott, Williams \& Wilkins; 2002. pp. 10591128.

14. Ostapowicz GM, Fontana R, Schiødt F, Larson A, Davern T, Steven Han H, McCashland T, Shakil A, Hay J, Hynan L, et al. Results of a prospective study of acute liver failure at 17 tertiary care centers in the United States. Ann Intern Med 2002;137:947-954.

15. Larrey D. Epidemiology and individual susceptibility to adverse drug reactions affecting the liver. Semin Liver Dis 2002;22:145-155.

16. Carson JL, Strom BL, Duff A, Gupta A, Das K. Safety of nonsteroidal antiinflammatory drugs with respect to acute liver disease. Arch Intern Med 1993;153:1331-1336. 
17. Brown SJ, Desmond PV. Hepatotoxicity of antimicrobial agents. Semin Liver Dis 2002;22:157-167.

18. Kaplowitz N. Drug-induced liver injury. Clin Infect Dis 2004;38:S44-S48.

19. U.S. Public Health Service. Hepatic toxicity of pyrazinamide used with isoniazid in tuberculous patients. Am Rev Respir Dis 1969;59:13.

20. Kaplowitz N. Biochemical and cellular mechanisms of toxic liver injury. Semin Liver Dis 2002;22:137-144.

21. Dufour DR, Lott JA, Nolte FS, Gretch DR, Koff RS, Seeff LB. Diagnosis and monitoring of hepatic injury: I. Performance characteristics of laboratory tests. Clin Chem 2000;46:2027-2049.

22. Dufour DR, Lott JA, Nolte FS, Gretch DR, Koff RS, Seeff LB. Diagnosis and monitoring of hepatic injury: II. Recommendations for use of laboratory tests in screening, diagnosis, and monitoring. Clin Chem 2000;46:20502068.

23. American Gastroenterologic Association Clinical Practice Committee. AGA technical review on the evaluation of liver chemistry tests. Gastroenterology 2002;123:1367-1384. 